\title{
LAND PRICES AND LOCATION OF FREIGHT TRANSPORT FACILITIES IN THE URBAN TRANSPORT PLANNING PROCESS
}

\author{
GIUSEPPE MUSOLINO \\ DIIES - Dipartimento di Ingegneria dell'Informazione, delle Infrastrutture e dell'Energia Sostenibile, \\ Università Mediterranea di Reggio Calabria, Italy
}

\begin{abstract}
On behalf of the land use-transport interaction paradigm, the paper analyses the relationships between land prices and transport costs variables in urban area. The main objective of the analysis is to obtain quantitative insights to support decision-makers in the location process of freight transport facilities, as the Urban Distribution Centres (UDCs). The preliminary results presented in the paper concern the spatial distribution of average sales prices of some selected categories of residential and commercial properties and the relationships between average sales prices of the category of shops and the distance from the Central Business District (CBD). The data used are part of an extended data-base concerning real-estate prices, transport costs and accessibility, socio-economic conditions of population and workers, and structural characteristic of the coastal city of Reggio Calabria (Italy). The analysis confirms the correlation existing between the average prices of commercial properties (shops) and the distance from CBD, due to the mono-centric structure of the city.
\end{abstract}

Keywords: land prices, transport cost variables, urban distribution centres planning, urban area.

\section{INTRODUCTION}

It is commonly accepted that there is a two-way relationship between land use and transport in urban areas. Land use affects transport, conditioning passengers and freight demand flows' patterns. Transport influences the spatial organisation and the economy, affecting activities location, real-estate prices and trade patterns [1]-[3].

In the sphere of the above paradigm, the analysis focuses on the relationships between real-estate prices and transport costs in urban area. Two are the main research approaches about this topic in literature.

The former has a more theoretical background (see Alonso [4], Muth [5] and Mills [6]). The basic assumption is that decision-makers are generally attracted by locations with better accessibility to the urban services and activities. This behaviour generates higher prices of real-estates having these characteristics. The first works used as transport variable the distance from the Central Business District (CBD), as it generally presents the highest density of activities and land use mix. Literature concerning this approach is very rich and it can be included in the broad discipline called urban economics.

The latter has more empirical nature and it is based on the hedonic price concept [7]. Some studies analyse the correlation between the level of service of public transport (e.g. railways/bus services) and real-estate values (e.g. properties located close to the stations) [8][10]. The preliminary results presented in the paper concerns the spatial distribution of average sales prices of residential and commercial properties and the correlation between average sales prices of the commercial properties (shops) and the distance from CBD. The empirical results show a mono-centric structure of the analysed city.

The results presented in the paper are part of an extended survey finalized to obtain relationships among observed data related to four classes of variables: real-estate prices, transport costs and accessibility, socio-economic segments of population and workers, 
structural characteristics of the urban area. The study area is the municipality of Reggio Calabria and observed data are aggregated at zonal level.

The following part of the paper is articulated as follows. Section 2 describes the characteristics of the data-set in terms of zones of the study area and estimated variables belonging to each class. Section 3 presents two analyses on some observed variables of the data-set.

The first analysis concerns the spatial distribution of average sales price per zone of some classes of residential and commercial properties. The second one concerns the relationships between average sales prices of shops and a typical transport cost attribute, as the minimum distance on the road network of a zone from the CBD. The last section reports the research perspectives.

\section{STUDY AREA AND DATA-SET}

The study area includes the coastal city of Reggio Calabria. The city extends along the coast for about $32 \mathrm{~km}$ and from the coastline to the inner areas for approximately $30 \mathrm{~km}$, with hilly and mountainous parts. It occupies a surface of 236 square kilometres and the population is of 180,353 inhabitants.

The study area has a central district (Fig. 1), where a mix of dense residential, economic and services activities are present. The central district is composed of a CBD and an urban ring (UR). The central district has been completely rebuilt after a disastrous earthquake in 1908, and it has a hippodamian structure with broad roads along the coastline and sea-mountain directions, that intersect at right angles.

The municipal and regional governments, university, hospital, courthouse and business centre are located in the central district. Furthermore, there is a dense mix of residential, commercial and service activities.

The city has a port, not far from the CBD, where there are passenger services ensuring daily connections with the closer city of Messina and the Aeolian Islands.

The study area presents also a Sub-urban Ring (SR), where more dispersed residential and economic activities are located. The SR was characterized, in general, in the last decades by an unplanned urban development with lack, or absence in some cases, of adequate transport infrastructures and services.

The data-set is composed of four categories of data:

- $\quad$ average real-estate prices obtained from data-base of the Observatory of the Real-Estate Market for year 2010 (www.agenziadelterritorio.it);

- travel costs on urban transport network estimated by means of GoogleMaps $($ software;

- socio-economic variables related to population and employment belonging to data-base ISTAT (census data, year 2001);

- $\quad$ structural characteristics of the study area.

The data are average values per zone, according to a zoning operated on the study area (see Fig. 1):

- $\quad$ CBD includes zones 18, 21, 22 and 23;

- $\quad$ Northern Urban Ring (UR_N) includes zones 12, 13, 14, 15, 16, 17, 19 and 20;

- Southern Urban Ring (UR_S) includes zones 24, 25, 26, 27, 28, 30, 31, 32, 33, 34, 35, and 36;

- $\quad$ Northern Sub-urban Ring (SR_N) includes zones 1, 2, 3, 4, 5, 6 and 7;

- Southern Sub-urban Ring (SR_S) includes zones 8, 9, 10 and 11. 


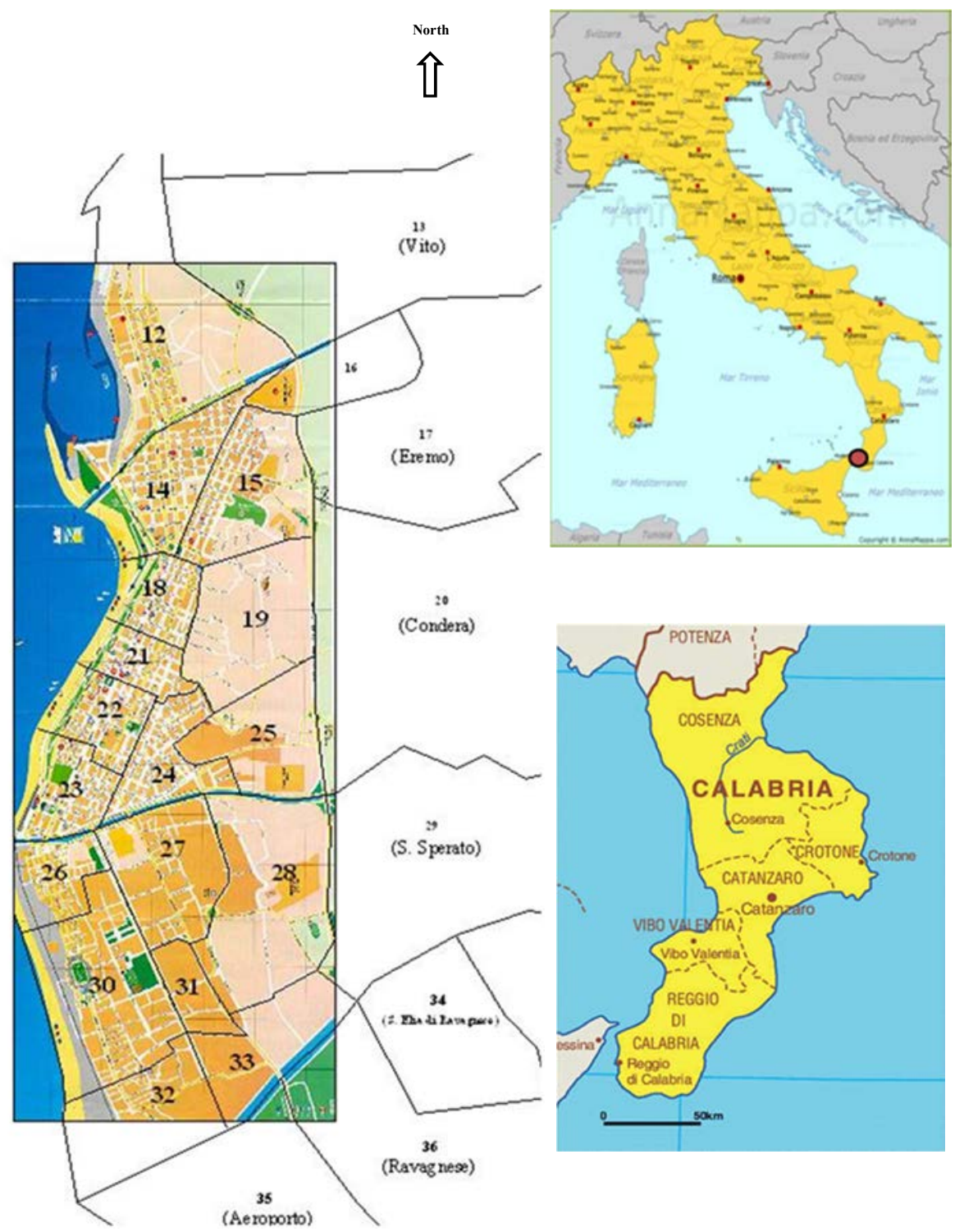

Figure 1: Central district of the municipality of Reggio Calabria (Italy).

The real-estate attributes are aggregated observations per zone: average sale price per square unit, average rental price per square unit, number of buildings, areas of buildings. The observatory of real-estate market considers the following classification (Fig. 2) of typologies:

- residential: high-medium flats, low flats (the difference between the two classes is according to a qualitative point of view), (semi-)detached;

- commercial: shops, depots, laboratories;

- service: offices. 

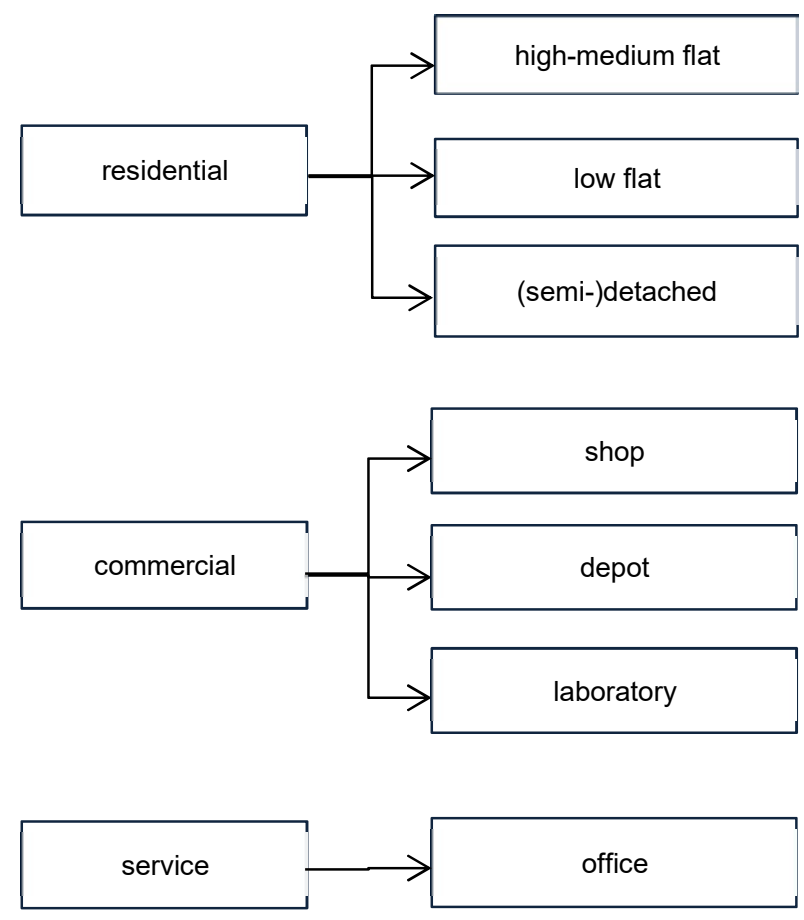

Figure 2: Structure of the data-base of real-estates prices.

The following variables of the urban transport system have been estimated per each zone of the study area:

- distance on the road network from CBD, d_CBD $(\mathrm{km})$, length of the shortest path on the road network [11]-[13]; between the identified centroid of each zone and the CBD of the municipality of Reggio Calabria (the City Hall is assumed as centroid of the CBD);

- (congested) travel time on the network from $C B D, t t C C B D(h)$, (congested) travel time (during morning period between 7:00 and 9:00 a.m.) along the shortest path of the road network between the centroid of each zone and the CBD of the municipality of Reggio Calabria;

- distance from highway access, d_HGW $(\mathrm{km})$, length of the shortest path on the road network between the centroid of each zone and the closest highway access;

- presence of a rail station, rail_sta (0/1), dummy variable equal to $1=$ if there is at least one railway station in the zone; $0=$ otherwise;

- active accessibility, act_acc, of zone o of the study area for a group of individuals (s), defined as a measure of the opportunity of reaching activities located in different zones of the study area travelling from zone o (see eqn (1)):

$$
\text { act_acc }{ }_{\mathrm{o}}^{\mathrm{s}}=f\left(\mathrm{x}_{\mathrm{o}}^{\mathrm{s}}\right),
$$

where $\mathrm{x}_{\mathrm{o}}^{\mathrm{s}}$ : distance, or travel time, or disutility for group s related to zone $\mathrm{o}$, and $f()$ : functional transformation; 
- $\quad$ passive accessibility, pas_acc, of zone $\mathrm{d}$ of the study area for a group of individuals (s), defined as a measure of the opportunity of activities located in zone $d$ to be reached from different zones of the study area (see eqn (2))

$$
\text { pas_acc }{ }_{\mathrm{d}}^{\mathrm{s}}=f\left(\mathrm{x}_{\mathrm{d}}^{\mathrm{s}}\right) \text {, }
$$

where $\mathrm{X}_{\mathrm{d}}^{\mathrm{s}}$ : distance, or travel time, or disutility for group s related to zone $\mathrm{d}$, and $f()$ : functional transformation.

The following socio-economic variables has been considered: population, households, employment, commerce employment, service employment, population density, employment density, commerce employment density, service employment density. A structural characteristic of the study area is the proximity of a zone to the coastal line.

\section{FIRST EVIDENCES FROM AN EMPIRICAL ANALYSIS}

This section reports the first evidences from an analysis on the spatial distribution of average sales prices of selected categories of residential and commercial properties and the relationship between average sales prices of shops vs. distance from the CBD.

\subsection{Spatial distribution of average sales prices}

The section reports the spatial distribution of average sales prices for each zone of some categories of residential and commercial properties, selected from the data base represented in Fig. 2. It is worth noting that each value is not important in absolute terms, but in relation to the other ones in order to provide a quantitative measure of the capacity of each zone to attract activities in relation to the others of the study area. Table 1 reports the minimum, maximum, average and standard deviation values of average sales prices for each category of real estates identified in the data base of Fig. 2. For what concerns the minimum average sales prices, zone 2 is a hilly part of the study area belonging to the SR that presents the minimum values in all the categories of properties. The maximum average sales prices of flats are presents in the four zones 18,21, 22, 23 of the CBD, while the maximum average sales prices of shops and offices are present in the two zones 21 and 22, which are closer to the City Hall. The maximum value of sales prices of (semi-)detached properties is present in zone 6 , which is a peripheral zone located along the coastal line with valuable buildings and in which there is, only case in the sub-urban ring, an ordered urban structure.

Table 1: Minimum, maximum, average and standard deviation of average sales prices per category of real estate.

\begin{tabular}{|l|c|c|c|c|c|c|}
\hline & Min & Zone & Max & Zone & Average & st. dev. \\
\hline & Euro/mq & & Euro/mq & & Euro/mq & Euro/mq \\
\hline High-medium flat & 520.0 & 2 & 2600.0 & $18 / 21 / 22 / 23$ & 1235.3 & 425.2 \\
\hline Low flat & 450.0 & 2 & 2300.0 & $18 / 21 / 22 / 23$ & 1132.8 & 369.8 \\
\hline (Semi-)detached & 570.0 & 2 & 2250.0 & 6 & 1186.6 & 246.1 \\
\hline Depots & 370.0 & 2 & 1400.0 & $18 / 21 / 22 / 23$ & 741.4 & 189.4 \\
\hline Shops & 660.0 & 2 & 4500.0 & $21 / 22$ & 1822.5 & 729.3 \\
\hline Offices & 555.0 & 2 & 2750.0 & $21 / 22$ & 1446.3 & 392.0 \\
\hline Laboratories & 410.0 & 2 & 1300.0 & 18 & 778.1 & 199.7 \\
\hline
\end{tabular}


Histograms in Figs 3-5 describe respectively the spatial distribution of average sales prices of high-medium flats, low flats and shops.

Concerning high-medium flats and low flats histograms (Figs 3 and 4), it emerges that they have a similar pattern, with a peak of observed values in the zones of the CBD of the municipality (zones 18, 21, 22, 23) and with observed values that progressively declining as far from CBD. For both categories of residential properties, average sales prices in the Northern and Southern parts of UR and SR districts present similar values.

Pattern of shops' sales prices is slightly different (see Fig. 5), showing peak values in zones 14, 21 and 22 belonging to central district. In the peripheral zones, the values are not far from an average value. Average sales prices of shops in the Northern part of UR district (UR_N) are higher than the ones of shops located in the Southern part (UR_S).

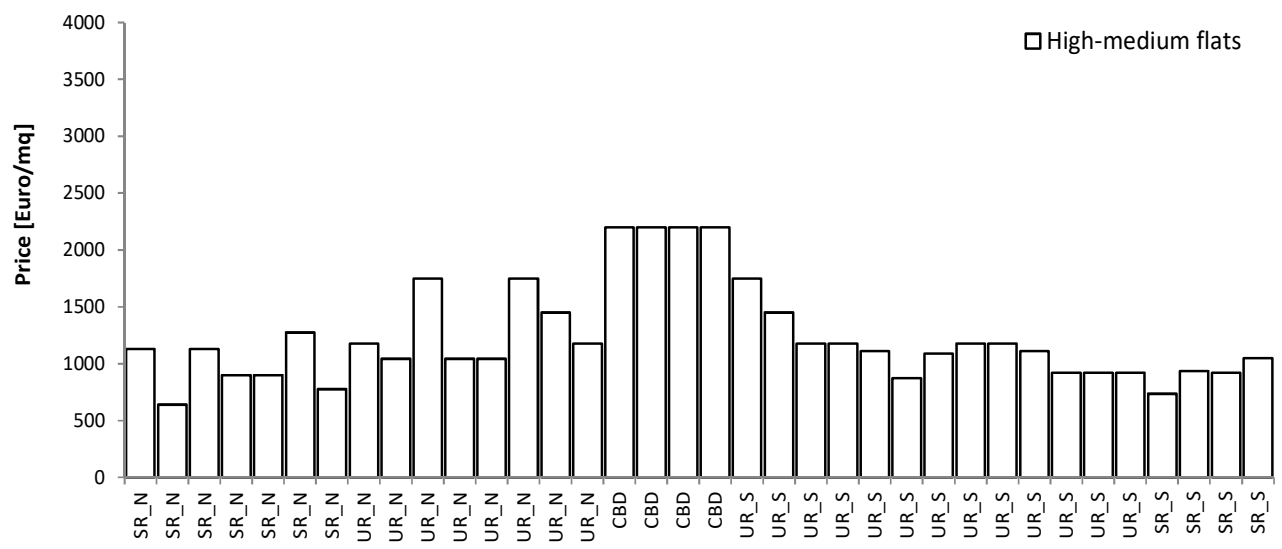

Figure 3: High-medium flats: spatial distribution of sales prices among CBD, UR and SR $(\mathrm{N}=$ North, $\mathrm{S}=$ South $)$.

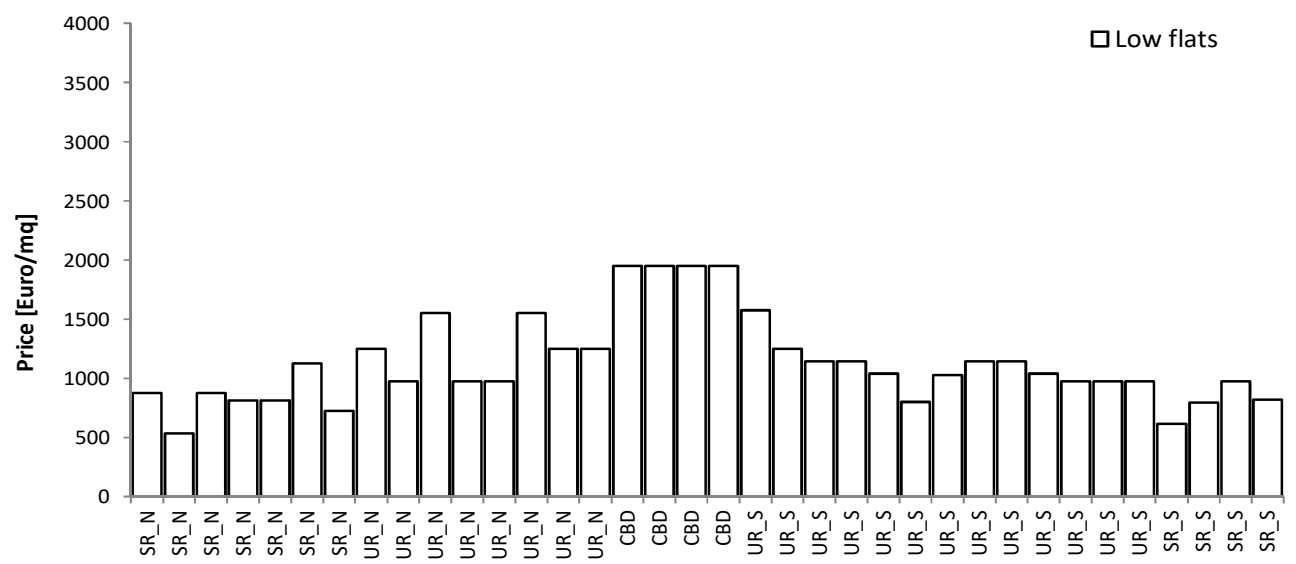

Figure 4: Low flats: spatial distribution of sales prices among CBD, UR and $\mathrm{SR}(\mathrm{N}=$ North, $\mathrm{S}=$ South). 


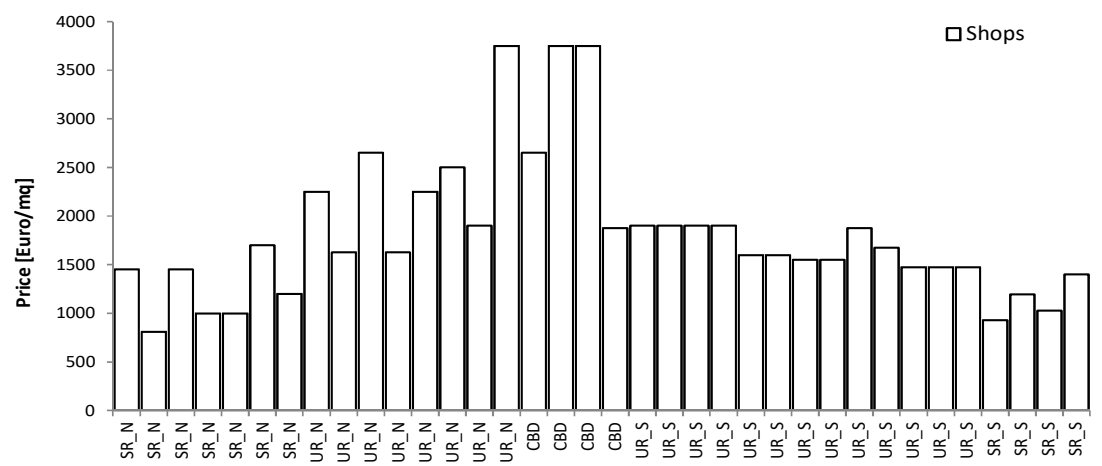

Figure 5: Shops: spatial distribution of sales prices among CBD, UR and SR ( $\mathrm{N}=$ North, $\mathrm{S}=$ South).

\subsection{Focus on shops: average sales prices vs. distances from the CBD}

This paragraph focuses on the category of shops, analysing the relationship between sales prices and distance from CBD.

The analysis supports the identification of quantitative insights concerning the location of freight transport facilities as the Urban Distribution Centres (UDCs). Among the main elements to be considered in the UDC planning [14]-[19], the identification of available urban areas is an important activity, especially in coastal cities with a commercial port [20]. The current tendency of UDCs is to move away from core urban areas toward sub-urban and extra-urban areas [21]. This relocation benefits logistic operators of having cheaper, larger and more accessible (to nodes belonging to national and international transport networks: ports, airports, intermodal terminals, motorways interchanges) land parcels, on one side; but, it causes an increase in freight vehicle-km travelled within the urban area to reach final receivers, who remain concentrated inside urban core areas. The scatterplot between average sales prices of shops vs. minimum distance from CBD (Fig. 6) shows a clear declining trend of average sales prices as the distance from the $\mathrm{CBD}$ increases.

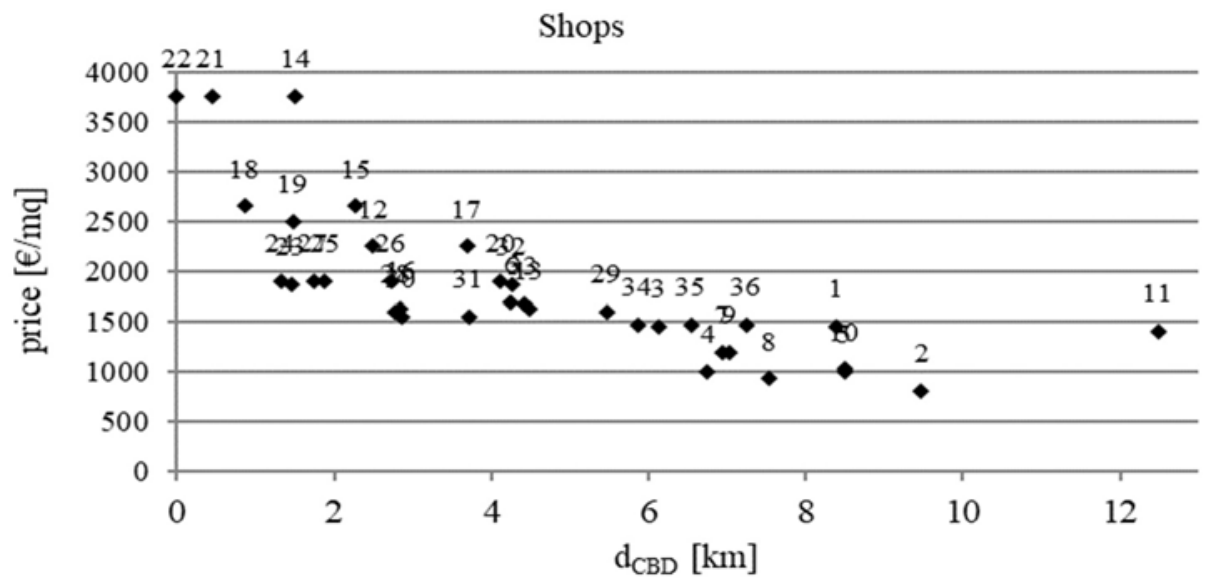

Figure 6: Average sales prices vs. distance from CBD for shops. 
Zones 21 and 22, belonging to the CBD, present the highest values of prices; while the high average sales prices of zone 14, belonging to the Northern part of UR district (UR_N), are due to the presence of several commercial activities.

In a second step of the analysis, a price function for the category of shops is specified and calibrated:

$$
\text { price }=\operatorname{price}(\mathbf{x}, \alpha) \text {, }
$$

where price: average sales prices of shops; price(): price function; $\mathbf{x}$ : vector of attributes; $\alpha$ : vector of parameters to be calibrated.

The following three specifications have been tested:

$$
\begin{gathered}
\text { price }_{\mathrm{i}}=\alpha_{1}+\alpha_{2} \mathrm{~d}_{\mathrm{CBD}, \mathrm{i}} \quad \forall \mathrm{i} \in \mathrm{Z}, \\
\text { price }_{\mathrm{i}}=\left\{\begin{array}{l}
\alpha_{3} \text { if zone } \mathrm{i} \in \mathrm{CBD}, \\
\alpha_{4} \text { if zone } \mathrm{i} \in \mathrm{UR}, \\
\alpha_{5} \text { if zone } \mathrm{i} \in \mathrm{SR},
\end{array}\right. \\
\text { price }_{\mathrm{i}}=\alpha_{6} \exp \left(-\alpha_{7} \mathrm{~d}_{\mathrm{CBD}, \mathrm{i}}\right) \quad \forall \mathrm{i} \in \mathrm{Z},
\end{gathered}
$$

where $\mathrm{i}$ is the generic zone belonging to the set of zones $\mathrm{Z}$.

Eqn (4) is a linear specification of prices function, eqn (5) is a step function with an average value of price per each macro-zone of the municipality (SR, UR, CBD), eqn (6) is an exponential function. Eqns (4) and (6) have the distance from the CBD as independent variable (attribute).

The vector of parameters, $\alpha$, is calibrated using a weighted Least Squares Method, as follows:

$$
\text { objective: } \text { minimum } \sum_{\mathrm{i}=1 \ldots \mathrm{z}}\left(\text { price }_{\mathrm{i}, \mathrm{obs}}-\text { price }_{\mathrm{i}}\left(\mathrm{d}_{\mathrm{CBD}}, \boldsymbol{\alpha}\right)\right)^{2},
$$

calibrated parameters: $\alpha$

where $_{\text {price }}$ i,obs is the observed average sales prices of shops in zone $\mathrm{i}$.

The values of calibrated parameters of eqns (4)-(6) by means of optimization model of eqn (7) are reported in Table 2. The values of $\alpha_{1}, \alpha_{3}$ and $\alpha_{6}$, which correspond to the maximum value of price for $\mathrm{d}_{\mathrm{CBD}}=0$, are similar in the three models. The variation of price per unit of distance in the linear model of eqn (4) is -187.6 Euro $/ \mathrm{km}$, while this variation

\begin{tabular}{|c|c|c|c|c|}
\hline Equation & \multicolumn{3}{|c|}{ Parameters } & $\mathrm{R}^{2}$ \\
\hline \multirow{2}{*}{4} & $\alpha_{1}$ & & $\alpha_{2}$ & \multirow{2}{*}{0.56} \\
\hline & 2669.5 & \multicolumn{2}{|c|}{-187.6} & \\
\hline \multirow{2}{*}{5} & $\alpha_{3}$ & $\alpha_{4}$ & $\alpha_{5}$ & \multirow{2}{*}{0.43} \\
\hline & 2785.0 & 1925.0 & 1196.0 & \\
\hline \multirow{2}{*}{6} & \multicolumn{2}{|l|}{$\alpha_{6}$} & $\alpha_{7}$ & \multirow{2}{*}{0.65} \\
\hline & \multicolumn{2}{|c|}{2686.8} & -0.101 & \\
\hline
\end{tabular}
ranges values from 258.0 Euro $/ \mathrm{km}$ (for $\mathrm{d}_{\mathrm{CBD}}=1 \mathrm{~km}$ ) to 157.0 Euro $/ \mathrm{km}$ (for $\mathrm{d}_{\mathrm{CBD}}=12 \mathrm{~km}$ ) in the exponential model of eqn (6). The highest value of $\mathrm{R}^{2}$ is obtained for the exponential model $\left(R^{2}=0.65\right)$, followed by the linear one $\left(R^{2}=0.56\right)$.

Table 2: Calibrated parameters of eqns (4)-(6). 


\section{CONCLUSIONS}

The paper focused on the relationships between real-estate prices and transport costs in urban area. The observed patterns of the spatial distribution of average sales prices and of average sales price of shops vs. distance from the CBD confirm the mono-centric structure of the coastal city of Reggio Calabria. The city has an attractive CBD where residential, commercial and service activities are concentrated and mixed. A densely inhabited urban ring and a sub-urban ring, where the residences are more dispersed, gravitate around the CBD.

The preliminary results of the research presented in the paper could be applied to other coastal cities, which have the same dimensions and structure of Reggio Calabria.

Future work will regard the consideration of further attributes in the models, that also take into account the presence of the port. The necessity to develop well-planned freight transport infrastructures assumes greater importance in coastal cities, where a commercial and passenger port generally exists, generating additional negative effects due maritime and road traffic. A multi-dimensional analysis, by means of the specification and calibration of hedonic prices models, will provide a larger spectrum of quantitative elements to urban transport planners.

\section{REFERENCES}

[1] Geurs, K.T. \& van Wee, B., Accessibility evaluation of land-use and transport strategies: Review and research directions. Journal of Transport Geography, 12, pp. 127-140, 2004.

[2] Russo, F. \& Musolino, G., Urban land-use transport interaction modelling: State of the art and applications. Urban Transport XIII, Urban Transport and the Environment in the 21st Century, ed. C.A. Brebbia, WIT Press: Southampton, pp. 525-534, 2007.

[3] Russo, F. \& Musolino, G., A unifying modelling framework to simulate the spatial economic transport interaction process at urban and national scales. Journal of Transport Geography, 24, pp. 189-197, 2012.

[4] Alonso, W., Location and Land Use, Harvard University Press: Cambridge, 1964.

[5] Muth, R.F., Urban residential land and housing markets. Issues in Urban Economics, eds H.S. Perloff \& L. Wingo, Johns Hopkins Press: Baltimore, 1968.

[6] Mills, E.S., Studies in the Structure of the Urban Economy, Johns Hopkins Press: Baltimore, 1969.

[7] Rosen, S., Hedonic prices and implicit markets: Product differentiation in pure competition. Journal of Political Economy, 82, pp. 34-55, 1974.

[8] McDonald, J. \& McMillen, D.P., Reaction of house prices to a new rapid transit line: Chicago's midway line, 1983-1999. Real Estate Economics, 32(3), pp. 463-486, 2004.

[9] Sun, W., Zheng, S. \& Wang, R., The capitalization of subway access in home value: A repeat-rentals model with supply constraints. Transportation Research Part A, 80, pp. 104-115, 2015.

[10] Des Rosiers, F., Thériault, M., Voisin, M. \& Dubé, J., Does an improved urban bus service affect house values? International Journal of Sustainable Transportation, 4, pp. 321-346, 2010.

[11] Marcianò, F.A., Musolino, G. \& Vitetta, A., Signal setting design on a road network: Application of a system of models in evacuation conditions. WIT Transactions on Information and Communication Technologies, vol. 43, WIT Press: Southampton and Boston, Part I, pp. PI443-PI454, 2010.

[12] De Maio, M.L. \& Vitetta, A., Route choice on road transport system: A fuzzy approach. Journal of Intelligent and Fuzzy Systems, 28(5), pp. 2015-2027, 2015. 
[13] Vitetta, A., A quantum utility model for route choice in transport systems. Travel Behaviour and Society, 3, pp. 29-37, 2016.

[14] Russo, F., Musolino, G. \& Trecozzi, M.R., A system of models for the assessment of an urban distribution center in a city logistic plan. WIT Transactions on the Built Environment, WIT Press: Southampton and Boston, pp. 799-810, 2013.

[15] Cirianni, F., Panuccio, P. \& Rindone, C., A comparison of urban planning systems between the UK and Italy: Commercial development and city logistic plan. WIT Transactions on the Built Environment, vol. 130, WIT Press: Southampton and Boston, pp. 785-797, 2013.

[16] Comi, A., Donnelly, R. \& Russo, F., Urban freight models. Modelling Freight Transport, eds L. Tavasszy \& G. de Jong, Elsevier, pp. 163-200, 2013.

[17] Russo, F. \& Comi, A., Urban freight transport planning towards green goals: Synthetic environmental evidence from tested results. Sustainability, 8(4), p. 381, 2016.

[18] Musolino, G., Vitetta, A. \& Polimeni, A., Freight vehicle routing with reliable link travel times: A method based on network fundamental diagram. Transportation Letters: The International Journal of Transportation Research, 10(3), pp. 159-171, 2018.

[19] Comi, A., Buttarazzi, B. \& Schiraldi, M., Smart urban freight transport: Tools for planning and optimising delivery operations. Simulation Modelling Practice Theory, 88, pp. 48-61, 2018.

[20] Russo, F., Musolino, G. \& Assumma, V., Competition between ro-ro and lo-lo services in short sea shipping market: The case of Mediterranean countries. Research in Transportation Business and Management, 19, pp. 27-33, 2016.

[21] Browne, M. \& Dablanc, L., Introduction to special section on logistics sprawl. Journal of Transport Geography. DOI: 10.1016/j.jtrangeo.2019.01.010. 